\title{
Craniosynostosis-fibular aplasia syndrome
}

INSERM

\section{Source}

INSERM. (1999). Orphanet: an online rare disease and orphan drug data base.

Craniosynostosis-fibular aplasia syndrome. ORPHA:1533

Craniosynostosis-fibular aplasia syndrome is an extremely rare genetic disease, reported in only 2 brothers to date, characterized by the combination of craniosynostosis (involving both coronal sutures), cong enital absence of the fibula, cryptorchidism, and bilateral simian creases. Intelligence is normal and an autosomal recessive mode of inheritance has been proposed. There have been no further reports in the literature since 1972. 